\title{
ANÁLISE COMPARATIVA DE SENSORES DE VELOCIDADE DE DESLOCAMENTO EM FUNÇÃO DA SUPERFÍCIE
}

\author{
JOSÉ P. MOLIN ${ }^{1}$, ADRIANO B. M. SOUZA ${ }^{2}$, GUSTAVO FONTANA ${ }^{2}$, \\ GUSTAVO K. NAGUMO ${ }^{2}$
}

\begin{abstract}
RESUMO: Um dos fatores que influencia diretamente no desempenho de sistemas mecanizados é a velocidade de deslocamento pela sua importância no planejamento e na execução das operações agrícolas. O objetivo deste trabalho foi avaliar a acurácia de quatro sensores de velocidade, em condições de superfície asfáltica, solo com cobertura vegetal, aclives e declives, acelerações e desacelerações, submetidos a velocidades representativas para aplicações agrícolas. Foram ensaiados dois modelos comerciais de sensores de radar, um sensor de GPS e um sensor óptico. Foram identificadas diferenças significativas para as situações de solo com cobertura vegetal, acelerações e desacelerações. Para a superfície asfáltica, em situação de velocidade constante, os sensores avaliados não apresentaram desempenho com diferença significativa. Os sensores tipo radar demonstraram ser influenciados pela superfície com cobertura vegetal. Na superfície asfáltica, sob condições de aceleração e desaceleração, o sensor de GPS apresentou retardo nos valores de velocidade quando comparado com os demais.
\end{abstract}

PALAVRAS-CHAVE: sensor, GPS, radar.

\section{ANALYSIS OF SPEED SENSORS PERFORMANCE ON DIFFERENT SURFACES}

ABSTRACT: One of the factors that influence directly the performance of mechanized systems is the forward speed that is important on planning and managing agricultural operations. The objective of this work was to evaluate the accuracy of four speed sensors, on paved road, vegetated surface, hills, increasing and reducing representative speeds for agricultural applications. Two commercial radars, a GPS sensor and an optical sensor were tested. For the paved road surface, under constant speed, no significant differences were observed on the performance. Radars were influenced by the vegetated surface. On paved road and under acceleration and deceleration the GPS sensor presented delay on its speed values when compared with the other sensors.

KEYWORDS: sensor, GPS, radar.

\section{INTRODUÇÃO}

A velocidade de deslocamento é um dos fatores de extrema importância no planejamento das operações agrícolas, influenciando diretamente no desempenho dos sistemas mecanizados. A correta determinação da velocidade de deslocamento dos conjuntos motomecanizados é fundamental para o gerenciamento da qualidade das operações, monitoramento do requerimento de potência, patinagem das rodas motrizes e da eficiência de tração, dentre outros. Nas operações de distribuição de insumos, em geral, a velocidade de deslocamento torna-se indispensável para que ocorra a correta dosagem de calcário, fertilizantes e defensivos. Com o advento das práticas de aplicação de insumos em taxa variada como função da variabilidade espacial da demanda, associados a práticas de agricultura de precisão, com auxílio de controladores, a detecção da velocidade passou a ser ainda mais importante,

\footnotetext{
${ }^{1}$ Eng ${ }^{0}$ Agrícola, Prof. Dr., Departamento de Engenharia Rural, ESALQ/USP, Piracicaba - SP, Fone: (0XX19) 3429.4165 - R: 211, jpmolin@esalq.usp.br

${ }^{2}$ Eng ${ }^{\circ}$ Agrícola, Mestrando em Máquinas Agrícolas, Departamento de Engenharia Rural, ESALQ/USP, Piracicaba - SP.

Recebido pelo Conselho Editorial em: 13-10-2004

Aprovado pelo Conselho Editorial em: 11-8-2005
} 
pois é um dos componentes da definição de dosagens. No gerenciamento de operações agrícolas, os tempos e as distâncias têm importância crescente na medida em que técnicas de otimização logística passam a ser adotadas rotineiramente e sensores de velocidade, associados a um sistema de coleta e registro de dados, são recursos indispensáveis nesse processo.

Os sistemas mecanizados mais avançados contam com monitores ou controladores eletrônicos, os quais utilizam informações de velocidade obtidas por meio de sensores. Os sensores de velocidade mais utilizados baseiam-se em radares ou sensores ópticos ligados às rodas dos tratores (ANTUNIASSI et al., 2001).

TOMPKINS et al. (1988) avaliaram vários equipamentos de medição de velocidade, tais como sensor de rodas, roda odométrica e radar com trator operando entre 1,31 e 2,78 $\mathrm{m} \mathrm{s}^{-1}$ em diferentes superfícies. Observaram que o coeficiente de variação da indicação da velocidade como função de tempo tendeu a ser maior para sensores em contato com rodas do que para o radar, exceto em superfícies de vegetação alta. O princípio de funcionamento do radar, segundo WERNECK (1996), baseia-se no efeito Doppler, o qual estabelece que, quando uma onda se propaga num meio qualquer e se reflete em algum objeto móvel, será refletida e terá uma freqüência diferente da onda incidente. Ainda, segundo o autor, outro sistema muito utilizado são os sensores magnéticos de roda, que correspondem a contatos fabricados com metal ferromagnético, sendo acionados por um campo magnético externo gerado por ímãs presos à roda do trator.

BENEZ et al. (2000) compararam o uso de radar e cronômetro para determinar a velocidade de deslocamento de um conjunto composto por trator e semeadora-adubadora de precisão, em ensaios de campo, em áreas com cobertura de aveia-preta. Observaram que a velocidade média obtida com o cronômetro foi ligeiramente superior à indicada pelo radar em todas as velocidades de deslocamento. ANTUNIASSI et al. (2001) avaliaram a influência do tipo de superfície e de mudanças no direcionamento do trator na medição da velocidade de deslocamento, utilizando sensores de roda e radares. Os autores concluíram que o sensor magnético de roda apresentou velocidade média indicada maior do que o radar, apesar de ambos terem sido calibrados nas mesmas condições.

A determinação da velocidade instantânea a partir do sinal de um receptor de GPS é obtida pelo efeito Doppler. No movimento relativo dos satélites da constelação de GPS em relação a um veículo em movimento, portando, um receptor, a frequiência da transmissão de um sinal gerado pelos satélites é alterada quando recebida no veículo. O receptor de GPS calcula a velocidade por meio do desvio na freqüência (efeito Doppler) do sinal vindo de cada satélite. O desvio de frequiência é proporcional à velocidade relativa entre a antena e o satélite. Sabendo as posições dos satélites e a velocidade relativa entre o receptor e os satélites, é possível calcular a velocidade do receptor e o vetor direção. Esse princípio é obtido proporcionalmente à velocidade radial relativa. Uma vez que a velocidade radial dos satélites é conhecida, a velocidade radial do veículo em movimento pode ser, então, deduzida (HOFMANN-WELLENHOF et al., 1992).

O objetivo deste trabalho foi avaliar a acurácia de quatro sensores de velocidade em condições de solo com cobertura vegetal e superfície asfáltica, sob acelerações e desacelerações, aclives e declives, em velocidades representativas para aplicações agrícolas.

\section{MATERIAL E MÉTODOS}

O trabalho foi realizado no Departamento de Engenharia Rural da Escola Superior de Agricultura "Luiz de Queiroz" (ESALQ/USP) em Piracicaba - SP, no mês de outubro de 2003. Como veículo, foi utilizado um trator, marca Massey Ferguson, modelo 5285, 4x2.

O ensaio avaliou quatro diferentes tipos de equipamento: sensor de radar de velocidade, modelo DjRVS II da marca Dickey John ${ }^{\circledR}$, acoplado ao lado direito do trator; sensor de radar de velocidade, 
modelo RGSS-201 da marca Mid-Tech ${ }^{\circledR}$, acoplado ao lado esquerdo do trator - ambos os sensores de radar foram fixados próximo ao eixo dianteiro; receptor de GPS como sensor de velocidade, modelo SV18GPS desenvolvido pela Auteq ${ }^{\circledR}$ e que gera 100.000 pulsos por quilômetro, fixado no toldo do trator, e o sensor óptico com 240 pulsos por volta, marca Hohner ${ }^{\circledR}$, fixado na roda dianteira direita do trator. Todos os equipamentos foram acoplados ao trator seguindo as recomendações técnicas dos fabricantes e com corrente de alimentação de $12 \mathrm{~V}$. Para aquisição dos dados de tempo e número de pulsos de cada sensor, foi utilizado um cronodômetro, montado em uma bancada de instrumentação acoplada ao trator.

A calibração dos sensores foi realizada em superfície asfáltica, em percurso reto, em área interna do Departamento de Engenharia Rural da ESALQ/USP. Foi demarcado o espaço de $30 \mathrm{~m}$ a ser percorrido pelo trator, entre duas balizas posicionadas no início e no final do percurso. O trator estava equipado com um sensor fotoelétrico de feixe duplo com alinhamento a laser (modelo DT-30 marca $\mathrm{DTECH}^{\circledR}$ ), possuindo ajuste de velocidade de disparo de $50 \mathrm{~ms}$ (milisegundos). Ao passar pela primeira baliza, o dispositivo era acionado por meio de um relé que disparava o cronodômetro, e ao passar pela segunda baliza, o dispositivo era desacionado. Utilizou-se de cinco repetições para cada velocidade. As velocidades utilizadas, obtidas por meio do escalonamento de marchas, corresponderam a 1,60;3,20 e 4,10 $\mathrm{m} \mathrm{s}^{-1}$. Com o número de pulsos obtido para cada sensor, dividido pelo espaço percorrido de $30 \mathrm{~m}$, obteve-se o número de pulsos por metro.

Nos ensaios para o cálculo da velocidade média, foi utilizado o número de pulsos por metro obtido na calibração com o número de pulsos do cronodômetro, obtendo-se a distância considerada para cada sensor. Por meio da distância e do tempo do cronodômetro, calculou-se a velocidade média de cada sensor. Para aquisição de dados dos ensaios dos sensores, foram utilizados os mesmos equipamentos da calibração.

Os sensores foram avaliados em superfície regular de asfalto e solo com cobertura vegetal. $\mathrm{Na}$ superfície de asfalto, os ensaios foram realizados com o trator sob velocidade constante, acelerações, desacelerações, aclives e declives. No solo com cobertura vegetal, os sensores foram ensaiados apenas sob velocidade constante. Em todos os ensaios, utilizou-se de parcela única de $30 \mathrm{~m}$, e, para estabilização da velocidade, foi adotada distância de $45 \mathrm{~m}$ antes da primeira baliza. A alavanca de aceleração foi posicionada em rotação constante para cada velocidade ensaiada, permanecendo inalterada em todas as repetições realizadas.

No ensaio sob velocidade constante, utilizou-se de quatro velocidades para a condição de solo coberto $\left(0,62 ; 1,70 ; 3,04\right.$ e 4,05 $\left.\mathrm{m} \mathrm{s}^{-1}\right)$ e três velocidades para a condição de asfalto $(3,03 ; 4,31$ e $5,63 \mathrm{~m} \mathrm{~s}^{-1}$ ), selecionando diferentes marchas no trator, e procurando simular operações agrícolas representativas em nosso meio.

No ensaio sob aceleração, utilizou-se de espaço de 0,50 m, antes da primeira baliza, para partida do trator da posição estática e a partir de então a velocidade permanecia crescente em todo o percurso. A desaceleração foi realizada com o trator sob velocidade constante, retornando a alavanca do acelerador para a posição mínima, imediatamente após a passagem do trator pela primeira baliza. Em todo o percurso, o trator permaneceu em velocidade decrescente, passando na segunda baliza com velocidade próxima à nula.

Para aclives e declives, utilizou-se de uma rampa com inclinação longitudinal de 8,9\% (dado aferido com clinômetro). Analisou-se o erro da velocidade indicada em cada sensor, considerando que, para o sensor de GPS, a distância medida é equivalente à projeção horizontal, o que pode causar distorção no valor estimado da velocidade, interferindo na medição da distância. Em função da rampa, as velocidades obtidas foram de 1,66;2,96 e 4,30 $\mathrm{m} \mathrm{s}^{-1}$ para aclives e 1,80;3,11 e 4,53 $\mathrm{m} \mathrm{s}^{-1}$ para declives. Em ambas as situações, foi utilizada a mesma marcha e rotação. 
O trabalho foi delineado em esquema fatorial $(4 \times 6)$, inteiramente casualizado, com cinco repetições, correspondentes aos seguintes fatores de variação: quatro sensores (dois sensores de radar, um sensor de GPS e um sensor óptico), seis situações (solo coberto, asfalto, aclive, declive, aceleração e desaceleração), totalizando 24 tratamentos.

Para a situação de solo coberto, o ensaio foi realizado em área em que havia sido colhido milho para silagem seis meses antes. A caracterização da cobertura vegetal foi determinada com auxílio de um gabarito (quadrado de ferro), nas dimensões de $0,50 \times 0,50 \mathrm{~m}$, totalizando $0,25 \mathrm{~m}^{2}$ (área interna do gabarito). O quadro foi arremessado sobre a área, aleatoriamente, com três repetições. $\mathrm{O}$ material encontrado dentro do gabarito foi recolhido e secado em estufa para a determinação da quantidade de matéria seca existente na área do ensaio. Durante o ensaio em solo com cobertura vegetal, não se repetiu o tráfego do trator no mesmo percurso, a fim de evitar a deformação da vegetação.

\section{RESULTADOS E DISCUSSÃO}

O material amostrado na área utilizada para o ensaio em solo coberto (restos culturais de milho, ervas daninhas e outros) apresentou cobertura de matéria seca de $271 \mathrm{~g} \mathrm{~m}^{-2}\left(2.710 \mathrm{~kg} \mathrm{ha}^{-1}\right)$.

A calibração dos sensores foi realizada com o intuito de aferir os dados obtidos nos manuais fornecidos pelos fabricantes com os obtidos na calibração, sendo os resultados apresentados na Tabela 1. Como era esperado, o sensor óptico, pelas suas características, resultou no menor desvio-padrão.

TABELA 1. Freqüência de coleta de dados indicados pelos fabricantes dos sensores e número de pulsos por metro de deslocamento obtidos na calibração.

\begin{tabular}{lccc}
\hline \multirow{2}{*}{ Sensores } & \multirow{2}{*}{ Freqüência } & \multicolumn{2}{c}{ Calibração } \\
\cline { 3 - 4 } & & Pulsos por Metro & Desvio-Padrão \\
Óptico & 240 pulsos por volta & 100,97 & 0,06 \\
Radar Dickey John & $*$ & 97,62 & 0,26 \\
GPS & 100.000 pulsos km & 100,23 & 0,16 \\
Radar Mid-Tech & $*$ & 119,31 & 0,25 \\
\hline
\end{tabular}

* Dado não disponível na literatura que acompanha o produto.

Os resultados comparativos dos sensores de velocidade para a condição de solo coberto são apresentados na Tabela 2 .

TABELA 2. Velocidades médias observadas no ensaio realizado em superfície com cobertura vegetal para velocidade nominal de 0,$62 ; 1,70 ; 3,04$ e $4,05 \mathrm{~m} \mathrm{~s}^{-1}$.

\begin{tabular}{llccl}
\hline Sensor & \multicolumn{4}{c}{ Velocidade Média Observada $\left(\mathrm{m} \mathrm{s}^{-1}\right)$} \\
Óptico & $0,62 \mathrm{a}$ & $1,69 \mathrm{a}$ & $3,02 \mathrm{a}$ & $4,01 \mathrm{a}$ \\
Radar Dickey John & $0,63 \mathrm{a}$ & $1,72 \mathrm{c}$ & $3,07 \mathrm{a}$ & $4,09 \mathrm{c}$ \\
GPS & $0,62 \mathrm{a}$ & $1,70 \mathrm{ab}$ & $3,03 \mathrm{a}$ & $4,03 \mathrm{ab}$ \\
Radar Mid-Tech & $0,63 \mathrm{a}$ & $1,71 \mathrm{~b}$ & $3,05 \mathrm{a}$ & $4,04 \mathrm{~b}$ \\
\hline Velocidade nominal $\left(\mathrm{m} \mathrm{s}^{-1}\right)$ & 0,62 & 1,70 & 3,04 & 4,05 \\
\hline
\end{tabular}

Para cada velocidade nominal, médias seguidas de mesma letra não diferem entre si, pelo teste de Tukey, a $1 \%$ de probabilidade.

Observou-se ausência de diferença significativa nas velocidades indicadas pelos sensores para as velocidades nominais de 0,62 e 3,04 $\mathrm{m} \mathrm{s}^{-1}$. Já nas velocidades de 1,70 e 4,05 $\mathrm{m} \mathrm{s}^{-1}$, o sensor óptico apresentou velocidade inferior quando comparado com os radares, não apresentando diferença significativa com o sensor de GPS. Nessas velocidades, observou-se que o radar Dickey John resultou em velocidade indicada maior que o radar Mid-Tech, sendo que ambos apresentaram as maiores velocidades. 
Os resultados apresentados nas Tabelas 3; 4 e 5 são para as condições de velocidade constante em superfície asfáltica, aclive e declive, respectivamente. Nessas três situações, não foi encontrada diferença significativa entre os sensores analisados. Para a condição de superfície asfáltica, em situações de aceleração e desaceleração, os resultados são apresentados na Tabela 6.

TABELA 3. Velocidades médias observadas no ensaio realizado em superfície asfáltica para velocidade nominal de 3,$03 ; 4,31$ e $5,63 \mathrm{~m} \mathrm{~s}^{-1}$.

\begin{tabular}{|c|c|c|c|}
\hline Sensor & \multicolumn{3}{|c|}{ Velocidade Média Observada $\left(\mathrm{m} \mathrm{s}^{-1}\right)$} \\
\hline Óptico & $3,03 \mathrm{a}$ & $4,31 \mathrm{a}$ & $5,62 \mathrm{a}$ \\
\hline Radar Dickey John & $3,03 \mathrm{a}$ & $4,31 \mathrm{a}$ & $5,61 \mathrm{a}$ \\
\hline GPS & $3,03 \mathrm{a}$ & $4,31 \mathrm{a}$ & $5,61 \mathrm{a}$ \\
\hline Radar Mid-Tech & $3,03 \mathrm{a}$ & $4,31 \mathrm{a}$ & $5,63 \mathrm{a}$ \\
\hline Velocidade nominal $\left(\mathrm{m} \mathrm{s}^{-1}\right)$ & 3,03 & 4,31 & 5,63 \\
\hline
\end{tabular}

Para cada velocidade nominal, médias seguidas de mesma letra não diferem entre si, pelo teste de Tukey, a $1 \%$ de probabilidade.

TABELA 4. Velocidades médias observadas no ensaio realizado em superfície asfáltica sob situação de aclive para a velocidade nominal de 1,66;2,96 e 4,31 $\mathrm{m} \mathrm{s}^{-1}$.

\begin{tabular}{lccc}
\hline Sensor & & Velocidade Média Observada $\left(\mathrm{m} \mathrm{s}^{-1}\right)$ \\
\hline Óptico & $1,65 \mathrm{a}$ & $2,94 \mathrm{a}$ & $4,28 \mathrm{a}$ \\
Radar Dickey John & $1,66 \mathrm{a}$ & $2,94 \mathrm{a}$ & $4,29 \mathrm{a}$ \\
GPS & $1,65 \mathrm{a}$ & $2,94 \mathrm{a}$ & $4,28 \mathrm{a}$ \\
Radar Mid-Tech & $1,65 \mathrm{a}$ & $2,95 \mathrm{a}$ & $4,29 \mathrm{a}$ \\
\hline Velocidade nominal $\left(\mathrm{m} \mathrm{s}^{-1}\right)$ & 1,66 & 2,96 & 4,31 \\
\hline
\end{tabular}

Para cada velocidade nominal, médias seguidas de mesma letra não diferem entre si, pelo teste de Tukey, a $1 \%$ de probabilidade.

TABELA 5. Velocidades médias observadas no ensaio realizado em superfície asfáltica sob situação de declive para a velocidade nominal de 1,$80 ; 3,11$ e $4,53 \mathrm{~m} \mathrm{~s}^{-1}$.

\begin{tabular}{llcc}
\hline Sensor & & Velocidade Média Observada $\left(\mathrm{m} \mathrm{s}^{-1}\right)$ \\
\hline Óptico & $1,80 \mathrm{a}$ & $3,11 \mathrm{a}$ & $4,53 \mathrm{a}$ \\
Radar Dickey John & $1,81 \mathrm{a}$ & $3,12 \mathrm{a}$ & $4,54 \mathrm{a}$ \\
GPS & $1,80 \mathrm{a}$ & $3,11 \mathrm{a}$ & $4,53 \mathrm{a}$ \\
Radar Mid-Tech & $1,81 \mathrm{a}$ & $3,13 \mathrm{a}$ & $4,54 \mathrm{a}$ \\
\hline Velocidade nominal $\left(\mathrm{m} \mathrm{s}^{-1}\right)$ & 1,80 & 3,11 & 4,53 \\
\hline
\end{tabular}

Para cada velocidade nominal, médias seguidas de mesma letra não diferem entre si, pelo teste de Tukey, a $1 \%$ de probabilidade.

TABELA 6. Velocidades médias observadas no ensaio realizado em superfície asfáltica sob situações de aceleração e desaceleração.

\begin{tabular}{lcc}
\hline \multirow{2}{*}{ Sensor } & \multicolumn{2}{c}{ Velocidade Média Observada $\left(\mathrm{m} \mathrm{s}^{-1}\right)$} \\
\cline { 2 - 3 } & Aceleração & Desaceleração \\
Óptico & $1,24 \mathrm{c}$ & $1,13 \mathrm{a}$ \\
Radar Dickey John & $1,21 \mathrm{~b}$ & $1,16 \mathrm{~b}$ \\
GPS & $0,72 \mathrm{a}$ & $1,34 \mathrm{c}$ \\
Radar Mid-Tech & $1,21 \mathrm{~b}$ & $1,14 \mathrm{a}$ \\
\hline Velocidade nominal $\left(\mathrm{m} \mathrm{s}^{-1}\right)$ & 1,23 & 1,14 \\
\hline
\end{tabular}

Para cada situação, médias seguidas de mesma letra não diferem entre si, pelo teste de Tukey, a 1\% de probabilidade. 
Em superfície asfáltica e para a condição de aceleração, os sensores de radar não apresentaram diferença significativa na velocidade indicada, enquanto o sensor de GPS apresentou erro na ordem de $41 \%$ inferior em relação à velocidade nominal. Na condição de desaceleração, apenas o sensor óptico e o sensor de radar Mid-Tech não apresentaram diferença significativa na velocidade indicada. O sensor de GPS apresentou velocidade média $18 \%$ superior em relação à velocidade nominal. Foi observado que o sensor de GPS apresentou retardo na obtenção de velocidades na situação de aceleração e desaceleração, sendo essa diferença relacionada ao processamento de dados que geram o sinal de velocidade por conta de seu algoritmo interno.

Sobre o solo com cobertura vegetal, os sensores tipo radar demonstraram ser influenciados pela irregularidade na superfície. Já nas situações de mudanças bruscas de velocidade, como nos ensaios de aceleração e desaceleração, o sensor de GPS apresentou atraso na velocidade indicada, o que de alguma forma deve ser corrigido ou compensado para não comprometer significativamente a qualidade de operações dependentes da velocidade, especialmente nas bordas dos talhões, onde as máquinas apresentam mudanças acentuadas na velocidade em função de manobras.

\section{CONCLUSÕES}

Para a condição de superfície asfáltica, em situação de velocidade constante, os sensores avaliados não apresentaram diferença significativa entre si. Os sensores tipo radar foram influenciados pela cobertura vegetal. Sob superfície asfáltica, em condições de acelerações e desacelerações, o sensor de GPS apresentou retardo nos valores de velocidade quando comparado com os demais sensores.

\section{AGRADECIMENTOS}

Ao Eng ${ }^{0}$ Juarez Reno Amaral, ao técnico Áureo Oliveira e ao auxiliar Francisco de Oliveira, pela colaboração; à Profa. Dra. Sonia Maria Stefano Piedade, pelas sugestões e auxílio no delineamento e análise estatística; à empresa Auteq, pelo apoio para a realização deste trabalho.

\section{REFERÊNCIAS}

ANTUNIASSI, U.R.; FIGUEIREDO, Z.N.; GADANHA JUNIOR, C.D. Avaliação de sensores de velocidade em função do tipo de superfície e direção de deslocamento do trator. Engenharia Agrícola, Jaboticabal, v.21, n.1, p.74-81, 2001.

BENEZ, S.H.; SILVA. S. de L.; PEREIRA, J.O.; RICIERI, R.P. Comparação de dois métodos de medição de velocidade de deslocamento. In: CONGRESSO BRASILEIRO DE ENGENHARIA AGRICOLA, 29., 2000, Fortaleza. Anais... Fortaleza: Sociedade Brasileira de Engenharia Agrícola, 2000. 1 CD-ROM.

HOFMANN-WELLENHOF, B.; LICHTENEGGER, H.; COLLINS, J. Global Positioning System: theory and practice. New York: Springer-Verlag, 1992. 326 p.

TOMPKINS, F.D.; HART, W.E.; FREELAND, R.S.; WILKERSON, J.B.; WILHELM, L.R. Comparison of tractor ground speed measurement techniques. Transactions of the ASAE, St. Joseph, v.31, n.2, p.369-74, 1988.

WERNECK, M.M. Transdutores de velocidade. In: Transdutores e interfaces. Rio de Janeiro: LTC Livros técnicos e Científicos, 1996. p.119-34. 